\title{
A Blessing in Disguise
}

Whether or not the world will be markedly changed as a result of it, the fact has emerged that the recent 'oil crisis' has been far more of a blessing than a curse. To be sure, it has been a curse in threatening widespread disruption of industry and international trade, in causing some personal and institutional hardship, and, particularly for American environmentalists, in its employment as an excuse to push through the Alaska pipeline project and to threaten huge oil-shale and strip-mining developments. Moreover it may have accelerated the use of environmentally even more unsuitable sources of energy. But it has been a far wider blessing in, surely, making people recognize the increasing gravity of the situation of impending energy shortages while there is still time to "cushion the blow, and to realize that provision has to be made for what otherwise would have inevitably precipitated at least a radical change in human life. It has been a blessing in making people realize the dire need for economy in the use of energy and in other ways, and even to start practising it. And it has been a blessing for the environmental future in manners ranging from presaging the early saving of habitats to the development ultimately of 'clean' energy. For above all, it has made people very widely, and even politicians, wake up to reality and the need for action-let us hope in time.

We will now deal in turn with the problems indicated in each of the last four sentences, and with their to-behoped-for outcomes.

The profligate use of energy, particularly that derived from irreplaceable fossil fuels, has been giving many of us cause for increasing concern in recent years; for you cannot go on expanding human population and its aspirations indefinitely in a finite world. Yet an everincreasing, and latterly overwhelming, proportion of the world's energy was being derived from fossil fuels -be it petroleum or other earth-based oils, coal and bituminous shale, or natural gas. These are practically once-for-all sources of energy, built up by plant life over many millions of years, and usually some hundreds of millions of years ago. When once used, they probably can never be replaced-even over many thousands of years, in view of the changed circumstances on Earth, including Man's desecration of vegetation. The longer this profligate use of fossil fuels went on, the harder would be the blow of their running out before other sources of energy had been sufficiently developed by inventive Man. Now it is to be hoped that the warning has gone out sufficiently widely and in time-for the more careful husbanding of the remaining resources of fossil fuels and for the development of other sources of energy which will be more lasting and less devastating to the environment.

As for making people, at least in the over-developed countries, realize the dire need for economy in the use of energy, this has indeed been a blessing, and its practice has propitiously extended into other aspects of human life. Thus not only in several countries of western Europe have automobiles and other petroldriven vehicles been banned on one or two days a week, but concomitant or other shortages are making people generally more economical-either perforce through actual shortages, or through realizing the deterioration in prospects for the future supplies of many luxuries or even necessities in the face of inexorably increasing human population pressures. To some extent it seems that for many the quality of life is actually being improved as a result of these economies; there are now days on which we can walk safely on the streets and even ride our bicycles (incidentally, among the most economical of all known means of using energy).

That is one source of improvement in our environment-reducing the incidence of polluting monsters arrogantly driven at dangerous speeds in exponentiallyincreasing numbers. Another should be the saving of habitats and natural ecosystems through the curbing of pollution and reduction of tourism and the more wasteful uses of fuel for sport. Yet another could be the practical saving of life on Earth through softpedalling the development of fume-spewing supersonic transport aircraft threatening the ozone shield in the stratosphere. Meanwhile the 'oil crisis' has already engendered greatly increased interest in alternative sources of energy-nuclear fusion, solar, geothermal, hydroelectric, tidal, and otherwise, with often vastly increased sums voted for ad hoc developmental research. I have purposely omitted the development of nuclear fission energy, on which the greatest expenditure still continues very widely, because of its inherent dangersas indicated by Professor Edsall and others in the present and subsequent issues of this journal. Surely it is the 'clean' sources and means of use that should be stressed-particularly those greatest-of-all solar ones and, hopefully, nuclear fusion.

As for the need to wake up to reality and have real action-urgently, before it is too late to save our world at least as we know it-this has probably been the greatest contribution of the 'oil crisis' as already indicated above. To preserve dwindling resourcesincluding productive land-there should be a renunciation of economic growth for selfish or national ends and some further compromise by bringing back the windmills and sailing ships, as well as the horses and bicycles. To paraphrase further a leading architect of the European Economic Community, Sicco Mansholt, the world should tend towards zero growth in order to become in time a society for survival-of both Man and Nature. As is emphasized by our Advisory Editor Professor Paul R. Ehrlich later in the present issue, this applies most fundamentally to human population.

N. P. 